\title{
A medicinal herb Scutellaria lateriflora inhibits PrP replication in vitro and delays the onset of prion disease in mice
}

\author{
Martin Eiden, Fabienne Leidel, Barbara Strohmeier, Christine Fast and Martin H. Groschup* \\ Institute for Novel and Emerging Infectious Diseases, Friedrich-Loeffler-Institut, Federal Research Institute for Animal Health, Greifswald, Germany
}

\section{Edited by:}

Silke Vogelgesang, University of

Greifswald, Germany

Reviewed by:

Anja Brenn, University Medicine Greifswald, Germany

Susanne Krasemann, University of Hamburg Eppendorf UKE, Germany

\section{*Correspondence:}

Martin H. Groschup, Institute for

Novel and Emerging Infectious

Diseases, Friedrich-Loeffler-Institut,

17493 Greifswald-Insel Riems,

Germany.

e-mail: martin.groschup@fli.bund.de
Transmissible spongiform encephalopathies (TSE) are characterized by the misfolding of the host encoded prion protein $(\mathrm{PrPC})$ into a pathogenic isoform $\left(\mathrm{PrPSc}^{\mathrm{Sc}}\right)$ which leads to the accumulation of $\beta$-sheet-rich fibrils and subsequent loss of neurons and synaptic functions. Although many compounds have been identified which inhibit accumulation or dissolve fibrils and aggregates in vitro there is no therapeutic treatment to stop these progressive neurodegenerative diseases. Here we describe the effects of the traditional medicinal herb Scutellaria lateriflora (S. lateriflora) and its natural compounds, the flavonoids baicalein and baicalin, on the development of prion disease using in vitro and in vivo models. S. lateriflora extract as well as both constituents reduced the PrPres accumulation in scrapie-infected cell cultures and cell-free conversion assays and lead to the destabilization of pre-existing $\mathrm{PrPS}^{\mathrm{Sc}}$ fibrils. Moreover, tea prepared from S. lateriflora, prolonged significantly the incubation time of scrapie-infected mice upon oral treatment. Therefore S. lateriflora extracts as well as the individual compounds can be considered as promising candidates for the development of new therapeutic drugs against TSEs and other neurodegenerative diseases like Alzheimer's and Parkinson's disease.

Keywords: prion protein, inhibitor, Scutellaria lateriflora, baicalein, baicalin

\section{INTRODUCTION}

Transmissible spongiform encephalopathies (TSEs) are neurodegenerative diseases which are characterized by the accumulation and deposition of a pathogenic isoform $\left(\mathrm{PrP}^{\mathrm{Sc}}\right)$ of the host encoded cellular prion protein $\left(\mathrm{PrP}^{\mathrm{C}}\right)$ designated $\mathrm{PrP}^{\mathrm{Sc}}$. Both isoforms share the same amino acid sequence but differ in conformation, resistance to proteinase $\mathrm{K}(\mathrm{PK})$, and pathogenicity. $\mathrm{PrP}^{\mathrm{Sc}}$ tends to oligomerize by a seeded polymerization mechanism followed by the formation of multimers and eventually of fibril structures. This aggregation can be reproduced in an analogous manner in vitro, using cell-based as well as cell-free assays. The evolved $\operatorname{PrP}^{\mathrm{Sc}}$ like isoforms - termed $\mathrm{PrP}^{\mathrm{res}}$ - harbor similar biochemical characteristics like resistance to Proteinase $\mathrm{K}$ and detection by same antibodies.

Accumulation of $\mathrm{PrP}^{\mathrm{Sc}}$ in the central nervous system (CNS) is accompanied by neurological dysfunctions, neuronal vacuolation, and astrocytic gliosis. Although the exact disease causing mechanism is unknown to date, there is evidence for a general neurotoxicity of these aggregates, which deteriorate synaptic function and induce oxidative stress and membrane disruption (Soto and Estrada, 2008). Prion diseases belong to the group of protein misfolding diseases like Alzheimer's (AD), Parkinson's (PD), and Huntington's disease (HD), which are generally characterized by an incorrect folding process of a host encoded protein with a conformation different from its native structure. The misfolding is followed by a self-aggregation and polymerization of the protein according to a "seeding-nucleation" process (Jarrett and Lansbury, 1993).
As $\operatorname{Pr} \mathrm{P}^{\mathrm{Sc}}$ formation and aggregation is the central event in prion diseases, the inhibition of oligomer formation and fibril extension as well as the enhancement of fibril degradation are major targets for the development of therapeutic strategies against TSEs. Several substances have been identified which inhibit PrP ${ }^{\text {res }}$ formation and accumulation in vitro and prolonged survival in scrapie-infected animals: Congo red (Caughey and Race, 1992), branched polyamines (Supattapone et al., 2001), porphyrins and phthalocyanines (Priola et al., 2000; Caughey et al., 2007), heparan sulfate mimetics (Adjou et al., 2003), amphotericin (Mange et al., 2000), curcumine (Caughey et al., 2003; Yang et al., 2009), and tetracyclines (De Luigi et al., 2008). However, for various reasons none of these compounds has been included in prevention and treatment regimes for humans yet. Most recently two new substance classes, benzothiazoles (Geissen et al., 2011) and diphenylpyrazoles (Leidel et al., 2011), were identified by high-throughput screening approaches that inhibit $\mathrm{PrP}^{\text {res }}$ accumulation in cell culture models and prolong incubation times in scrapie-infected mice.

Other therapeutic strategies rely on passive immunization (White et al., 2003), RNA interference (Pfeifer et al., 2006), RNA aptamers (Proske et al., 2002), copper chelating antibiotics (Murakami-Kubo et al., 2004), or on the induction of autophagy by Lithium (Heiseke et al., 2009).

Recent studies on $\mathrm{AD}$ suggest that phenolic compounds like green tea epigallocatechin gallate (Rezai-Zadeh et al., 2005), herb extracts like grape seed polyphenolic extract (Wang et al., 2009; Liu et al., 2011), or medicinal herbs like Paeonia suffruticosa (Fujiwara 
et al., 2009) can be used for the treatment of neurodegenerative diseases.

The here presented study shows that the American skullcap Scutellaria lateriflora, a traditional medical herb in North America, exhibits strong anti-prion activity. Extracts of this plant have been traditionally used as sedative and for the treatment of insomnia, anxiety, or neuralgia (Foster, 1996). Moreover, we can show here that the crude aqueous extract inhibits prion propagation and dissolves prion aggregates in vitro. Continuous oral administration of S. lateriflora tea (water extract) significantly prolonged incubation times in scrapie-infected mice. Notably, the natural constituents, the flavonoids baicalein and baicalin-hydrate, exhibit the same inhibitory effects on prion propagation and dissolve existing fibrils.

\section{MATERIALS AND METHODS \\ FLAVONOIDS AND TEA OF SCUTELLARIA LATERIFLORA}

Baicalein and baicalein-hydrate were purchased from SigmaAldrich and solubilized in DMSO. The dried herb S. lateriflora was purchased from Goldener Zweig (Buchholz, Germany). Water extracts (tea) were prepared by mixing $30 \mathrm{~g}$ of sliced dry herbs in 1.01 boiling water for $30 \mathrm{~min}$. After cooling the tea was administered directly to mice. For in vitro experiments tea was lyophilized to yield dried extracts. In cell-based assays the dried material was resuspended in $\mathrm{H}_{2} \mathrm{O}$, concentrated by a factor of 10 (termed tea concentrate) and added to the cell culture medium. In cell-free conversion assay the dried extract was directly resuspended in the conversion buffer in a final volume of $20 \mu \mathrm{l}$.

\section{PROPAGATION OF SCRAPIE STRAINS}

C57Bl/6 mice were inoculated with cloned mouse scrapie strains RML intracerebrally (i.c.; $30 \mu$ l of $1 \%$ mouse brain homogenate) or intraperitoneally (i.p.; $50 \mu \mathrm{l}$ of $1 \%$ brain homogenate). The health status of the mice was inspected daily, and their body weights were recorded weekly. After the onset of TSE-associated clinical symptoms (and weight loss, abnormal tail tonus, hind limb paralysis), the animals were euthanized. The incubation times were calculated as the time between inoculation and death. The brains were removed and kept as following: one half of each brain was stored at $-20^{\circ} \mathrm{C}$, and the other half was fixed in $4 \%$ neutral buffered formalin.

Pathogenic isoform for PrP conversion reactions was purified from brains of C57/B16 mice i.c. inoculated with mouse scrapie strain Me7. Brains were taken at the beginning of clinical symptoms in the animals and stored at $-20^{\circ} \mathrm{C}$. $\operatorname{PrP}^{\mathrm{Sc}}$ was purified according to Eiden et al. (2006).

\section{HEMATOXYLIN AND EOSIN STAINING AND IMMUNOHISTOCHEMISTRY}

Before embedding in paraffin the formalin fixed brain was cut at five different levels to reveal caudal medulla, rostral medulla, midbrain, thalamic, and frontal slices. Lesion profile scoring was carried out on Hematoxylin and Eosin (H\&E) stained sections according to standard methodology (Fraser and Dickinson, 1968). For immunohistochemistry samples were processed (with minor modifications) as described previously (Hardt et al., 2000). Three micrometers section were de-paraffinized and rehydrated. Pretreatment included an incubation step with $98 \%$ formic acid
(15 $\mathrm{min}$ ) and blocking of the endogenous peroxidase activity with $3 \% \mathrm{H}_{2} \mathrm{O}_{2} /$ methanol $(30 \mathrm{~min}$ ) followed by autoclaving in citrate buffer ( $\mathrm{pH}$ 6.0, $20 \mathrm{~min}$ ). The monoclonal antibody SAF 84 was applied at a dilution of 1:2000 for $2 \mathrm{~h}$ at room temperature and detected by avidin-biotin-horseradish peroxidase (Vector Elite). Color reactions were finally developed using diaminobenzidine (DAB) substrate.

\section{PROTEINASE K DIGESTION AND SODIUM PHOSPHOTUNGSTIC ACID PRECIPITATION}

Mouse brain samples $10 \%(\mathrm{w} / \mathrm{v})$ were prepared in lysis buffer $(0.42 \mathrm{mM}$ sucrose solution containing $0.5 \%$ deoxycholic acid sodium salt (DOC) and $0.5 \%$ Non-idet P40) and incubated with PK $\left(50 \mu \mathrm{g} / \mathrm{ml}\right.$, final concentration) for $60 \mathrm{~min}$ at $55^{\circ} \mathrm{C}$. Reactions were stopped with pefabloc (Roche) followed by incubation with $0.3 \%(\mathrm{w} / \mathrm{v})$ phosphotungstic acid precipitation (PTA) and selective precipitation of $\mathrm{PrP}^{\mathrm{Sc}}$ according to Gretzschel et al. (2005).

\section{PRP CONVERSION REACTION}

Cell-free conversion studies were performed as described before (Eiden et al., 2006; Kupfer et al., 2007). For the conversion reaction $400 \mathrm{ng}$ of recombinant ovine $\mathrm{PrP}^{\mathrm{C}}$, expressed in E. coli, was incubated with 200-400 ng of purified $\mathrm{PrP}^{\mathrm{Sc}}$ in a conversion buffer [50 mM citrate buffer ( $\mathrm{pH} 6.0$ ), $200 \mathrm{mM} \mathrm{KCl,} 5 \mathrm{mM} \mathrm{MgCl}_{2}$, and $1.25 \%$ sarkosyl; Horiuchi et al., 2000]. Standard conversion reactions were carried out for 3 days at $37^{\circ} \mathrm{C}$. Afterward, samples were incubated with PK (final concentration of $30 \mu \mathrm{g} / \mathrm{ml}$ ) for $1 \mathrm{~h}$ at $37^{\circ} \mathrm{C}$. PK was diluted in TN-buffer $(0.15 \mathrm{M} \mathrm{NaCl}, 0.05 \mathrm{M}$ Tris/ $\mathrm{HCl}$ $\mathrm{pH}$ 7.4). The reaction was stopped with PMSF (phenyl methansulfonyl fluoride; $10 \mathrm{mM}$ ). Twenty micrograms of a carrier protein (thyroglobulin) was added and the samples were incubated with a fourfold volume of methanol at $-20^{\circ} \mathrm{C}$ to precipitate the proteins. After centrifugation at $12000 \mathrm{~g}$ for $15 \mathrm{~min}$, the proteins were pelleted and resolubilized by heating to $95^{\circ} \mathrm{C}$ for $5 \mathrm{~min}$ in SDSPAGE loading buffer [1\% (w/v) SDS, $25 \mathrm{mM}$ Tris/HCl $\mathrm{pH} 7.4$, $0.5 \%$ mercaptoethanol, and $0.001 \%$ bromophenol blue].

Samples were separated on SDS-polyacrylamide gels containing $16 \%(\mathrm{w} / \mathrm{v})$ acrylamide/bisacrylamide, $0.375 \mathrm{M}$ Tris/ $\mathrm{HCl}(\mathrm{pH}$ $8.8), 0.5 \%(\mathrm{w} / \mathrm{v})$ SDS (sodium dodecyl sulfate), $0.06 \%(\mathrm{w} / \mathrm{v})$ APS (ammonium peroxydisulfate), and $0.06 \%$ (v/v) TEMED $\left(N, N, N^{\prime}, N^{\prime}\right.$-tetramethylethylenediamine) with a $4 \%$ stacking gel [4\% (w/v) acrylamide/bisacrylamide, $0.12 \mathrm{M}$ Tris/HCl (pH 6.8), $0.5 \%(\mathrm{w} / \mathrm{v})$ SDS, $0.2 \%$ APS, $0.2 \%(\mathrm{v} / \mathrm{v})$ TEMED].

For immunoblotting proteins were transferred in a semidry chamber to a polyvinylidene difluoride (PVDF) membrane. Membranes were then incubated in blocking buffer (PBS- $0.1 \%$ Tween 20,5\% non-fat dry milk powder) followed by incubation for $60 \mathrm{~min}$ with the monoclonal antibody (mab) P4 (RBiopharm), mab SAF-70 (SPIbio), or polyclonal antibody (pab) Ra 10 (Groschup et al., 1994, 1997). In contrast to mab P4, which detects ovine $\mathrm{PrP}^{\mathrm{C} / \mathrm{res}}$, pab Ral0 detects only murine $\mathrm{PrP}^{\mathrm{C} / \mathrm{Sc}}$. Membranes were washed three times for 10 min with PBS containing $0.1 \%$ Tween 20 and then incubated with a secondary antibody bound to alkaline phosphatase (Goat-anti-mouse-alkaline phosphatase or goat anti-rabbit-peroxidase). After washing, the chemiluminescence substrate CDP-Star (Tropix) was applied and membranes were incubated for $5 \mathrm{~min}$ before the light signals were 
recorded on a Versadoc Imaging System (Biorad). Visualization was carried out with the Biorad VersaDoc ${ }^{\mathrm{TM}}$ quantification software Quantity One. The percentage of converted substrate was calculated as: signal volume of $\mathrm{PrP}^{\text {res }}$ digested with $\mathrm{PK} /$ signal volume of $\mathrm{PrP}^{\mathrm{C}}$ without $\mathrm{PK}^{*} 10$. Conversion rates were calculated for each time point as a mean value from four independent reactions. For stripping, membranes were incubated twice for $15 \mathrm{~min}$ with a buffer containing $0.2 \mathrm{M}$ glycine ( $\mathrm{pH} 2.0)$ and 1\% SDS.

\section{PRPRES DETECTION FROM CELL CULTURE}

Two scrapie-infected mouse cell lines were used: $\mathrm{ScN}_{2} \mathrm{~A}$ cells [RML infected neuroblastoma- $\left(\mathrm{N}_{2} \mathrm{~A}\right)$-cells] and SMB-cells ("scrapie-mouse-brain," infected with strain 22F, a gift of TSE Resource Centre at the Institute for Animal Health, UK). $\mathrm{ScN}_{2} \mathrm{~A}$ cells were cultured in Opti-MEM, 10\% fetal calf serum (FCS), and $5 \% \mathrm{CO}_{2}$ at $37^{\circ} \mathrm{C}$. SMB-cells were cultured in MEM+ [MEM199, $10 \%$ newborn calf serum (NCS), 5\% FCS] and $5 \% \mathrm{CO}_{2}$ at $35^{\circ} \mathrm{C}$.

The cell-based assay was carried out according to Leidel et al. (2011) with two scrapie-infected mouse cell lines: $\mathrm{ScN}_{2} \mathrm{~A}$-cells and SMB-cells. These cells were adapted for dot blot procedure in 96-well plate format to identify potential inhibitors of $\mathrm{PrP}^{\mathrm{Sc}}$ formation. Compounds were resolved in DMSO and added to cells in eight replicates in concentrations of 10,100 , and $1000 \mu \mathrm{M}$ (final concentration). After 3 days of incubation in a $\mathrm{CO}_{2}$-incubator, the supernatants were removed and cells lysed in $100 \mu \mathrm{l}$ lysis buffer ( $50 \mathrm{mM}$ Tris/ $\mathrm{HCl}, 150 \mathrm{mM} \mathrm{NaCl}, 0.5 \%$ Na-deoxycholate, $0.5 \%$ TX-100, $\mathrm{pH} 8.0$ ). Lysates were or electrophoresed and immunoblotted as described in the previous section or dot blotted on PVDF membranes using a 96-well dot blot apparatus (Transblotter, Roth). Dot blotting membranes were dried for $1 \mathrm{~h}$ at $37^{\circ} \mathrm{C}$ and fixed sample incubated with DNAse $(100 \mu \mathrm{g} / \mathrm{ml})$ for $1 \mathrm{~h}$ at $37^{\circ} \mathrm{C}$. After rinsing the membranes twice with distilled water, the membrane was incubated with PK $(25 \mu \mathrm{g} / \mathrm{ml})$ for $90 \mathrm{~min}$ at $37^{\circ} \mathrm{C}$. The digestion was terminated using PMSF $(2 \mathrm{mM})$ and membranes were rinsed in $3 \mathrm{M}$ guanidium thiocyanate for $10 \mathrm{~min}$ followed by washing them five times in distilled water.

The incubation of the membrane with blocking buffer (PBS$0.1 \%$ Tween $20,5 \%$ non-fat dry milk powder) was followed by an incubation for 60 min with polyclonal antibody (pab) Ra 10 . Membranes were washed three times for 10 min with PBS containing $0.1 \%$ Tween 20 and then incubated with a secondary antibody bound to peroxidase (Goat anti-rabbit-PO). Afterward, the chemiluminescence substrate ECL (Roche) was applied and incubated on the membrane for $1 \mathrm{~min}$ before the light signals on the membrane were detected directly in a camera. The intensity of the $\mathrm{PrP}^{\mathrm{Sc}}$ signal of each well was quantified by using the Versadoc imaging system. The half maximal (50\%) inhibitory concentration $\left(\mathrm{IC}_{50}\right)$ of each compound was calculated from eight independent reactions.

\section{STATISTICAL ANALYSIS}

Survival times were analyzed by Kaplan-Meier Survival analysis using the log-rank test to compare the curves. The Statistical analysis was done using SigmaBlot statistical software (San Jose, CA, USA). Survival times are expressed as mean \pm SD.

\section{RESULTS}

The effect of S. lateriflora tea on the $\mathrm{PrP}^{\mathrm{res}}$ formation was first analyzed in vitro using two different scrapie-infected cell lines ( $\mathrm{SMB}$ and $\mathrm{ScN}_{2} \mathrm{~A}$-cells), which permanently accumulate $\mathrm{PrP}^{\mathrm{res}}$. When tea concentrate was added to the culture medium, a dose dependent reduction of $\mathrm{PrP}^{\text {res }}$ accumulation was observed in SMB as well as $\mathrm{ScN}_{2} \mathrm{~A}$-cells (Figure 1). Cells were cultivated in T25 flasks and incubated with increasing amounts of $S$. lateriflora tea for 3 days. After this time, cells were harvested and the level of PK-resistant $\mathrm{PrP}^{\mathrm{res}}$ was assessed by Western blotting. A dilution of 1:500 induced a reduction of $\mathrm{PrP}^{\text {res }}$ to $58 \%$ for $\mathrm{ScN}_{2} \mathrm{~A}$ (Figure 1A, lane 2) and to 64\% for SMB (Figure 1B, lane 2) cells compared to the control (Figures 1A,B, lane 1). Dilutions of 1:50 resulted in a reduction to $33 \%$ for $\mathrm{ScN}_{2} \mathrm{~A}$-cells (Figure 1A, lane 3 ) and $57 \%$ for SMB-cells (Figure 1B, lane 3). About 1:20 dilutions displayed reduction to $28 \%$ for $\mathrm{ScN}_{2} \mathrm{~A}$ (Figure 1A, lane 4) and $47 \%$ for SMB-cells (Figure 1B, lane 4 ) and reached values of $28.7 \%$ for $\mathrm{ScN}_{2} \mathrm{~A}$-cells (Figure 1A, lane 5) and $42.3 \%$ for SMBcells (Figure 1B, lane 5). Relative inhibition by tea is depicted in Figure 1C.

To test the direct effects of tea on the conversion of $\operatorname{PrP}^{\mathrm{C}}$ to PrPres, a cell-free conversion assay was used in which a purified murine $\mathrm{PrP}^{\mathrm{Sc}}$ template induced the conversion of recombinant cellular $\mathrm{PrP}^{\mathrm{C}}$ into a PK-resistant $\mathrm{PrP}^{\text {res }}$ fragment (Eiden et al., 2006; Kupfer et al., 2007). Newly converted PrP ${ }^{\text {res }}$-fragments were detected by mab P4 (Figure 2A, lanes 1-2), while $\mathrm{PrP}^{\mathrm{Sc}}$ aggregates were visualized by the polyclonal antibody Ra10 (Figure 2B, lanes 1-2). Dried tea extract (3,0.3, and $0.03 \mathrm{mg}$ respectively) was added to the conversion assay, inhibited $\mathrm{PrP}^{\mathrm{res}}$ formation and led to clearance of $\mathrm{PrP}^{\mathrm{res}}$-fragments (Figure 2A, lanes 3-6). Even $0.03 \mathrm{mg}$ caused a reduced $\mathrm{PrP}^{\text {res }}$ formation compared to the control (Figure 2A, lanes 7-8) by 23\%.

Similar results were seen in the case of dissolution of $\mathrm{PrP}^{\mathrm{Sc}}$ aggregates after PK digestion (Figure 2B). In contrast to the control (Figure 2B, lanes 1-2), $\mathrm{PrP}^{\mathrm{Sc}}$ aggregates were completely digested if co-incubated with $3.0 \mathrm{mg}$ dried tea extract (Figure 2B, lanes 3-4), as well as with $0.3 \mathrm{mg}$ (Figure 2B, lanes 5-6). About $0.03 \mathrm{mg}$ dried tea extract induced a partial disaggregation of $\mathrm{PrP}^{\mathrm{Sc}}$ aggregates (Figure 2B, lanes 7-8) by $40 \%$ compared to the control.

To further characterize the underlying inhibitory mechanisms, two main polyphenolic compounds of this herbal extract, the flavonoids Baicalin (baicalein 7-O-glucuronide) and its aglycone baicalein (5,6,7-trihydroxyflavone), were studied with regard to their inhibitory properties. Both components have been isolated from this herb previously (Awad et al., 2003) und were also identified in this study as ingredients in the tea by LCMS-IT-TOF hybrid mass spectrometry (data not shown). In addition, a structural analog to baicalein, the flavonoid epicatechin and quercetin were analyzed.

The potentially inhibitory effects on the PrPres accumulation and conversion were assayed by a cell-based dot blot assay system (Geissen et al., 2011) and the cell-free conversion assay. Structures, assay results, and half maximal (50\%) inhibitory concentrations $\left(\mathrm{IC}_{50}\right)$ of both compounds are summarized in Table 1. The cell-based dot blot assay was carried out with two different scrapie-infected SMB and $\mathrm{ScN}_{2} \mathrm{~A}$-cells again. Cells were seeded 

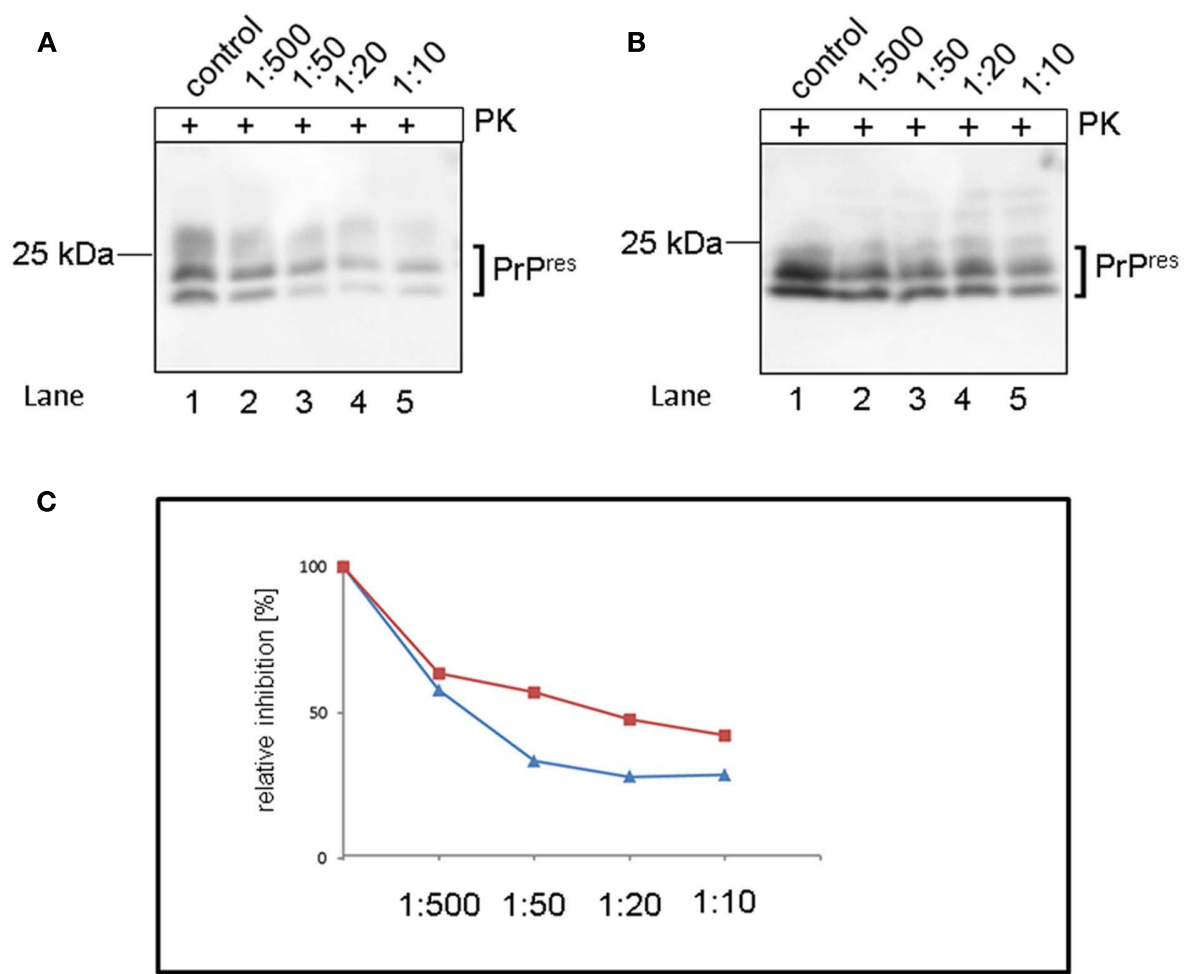

FIGURE 1 | Western blot analysis of inhibition of PrPres formation in scrapie-infected cells by tea concentrate of $\boldsymbol{S}$. lateriflora. (A) Tea concentrate of $S$. lateriflora inhibits PrPres formation in $\mathrm{ScN}_{2} \mathrm{~A}$-cells. Lane 1 shows PK-resistant fragments of the untreated control, lanes $2-5$ a sample incubated with increasing concentrations of tea concentrate of S. lateriflora: 1:500 (lane 2), 1:50 (lane 3), 1:20 (lane 4), and 1:10 (lane 5). (B) Inhibition of PrPres formation in SMB-cells by tea concentrate of $S$. lateriflora. PK-resistant fragments were detected in untreated control (lane 1), after incubation with tea in a 1:500 dilution (lane 2), 1:50 (lane 3), 1:20 and 1:10 (lane 5). Detection was carried out with pab Ra10 and analyzed by standard chemiluminescence method. (C) Relative inhibition (\%) of PrPres formation by tea concentrate for $\mathrm{SMB}$ (red line) and $\mathrm{ScN}_{2} \mathrm{~A}$ (blue line) cells. +, incubation with proteinase K (PK); u.d., undiluted. in 96 wells and incubated with decreasing concentrations of the corresponding flavonoids $(1 \mathrm{mM}, 100$ and $10 \mu \mathrm{M})$. $\mathrm{IC}_{50}$ values of Baicalein ranged from $138 \mu \mathrm{M}$ (SMB-cells) to $63.7 \mu \mathrm{M}\left(\mathrm{ScN}_{2} \mathrm{~A}\right.$ cells). Baicalin showed significantly lower inhibitory effects compared to baicalein in SMB-cells $\left(\mathrm{IC}_{50}:>1000 \mu \mathrm{M}\right)$ as well as in $\mathrm{ScN}_{2} \mathrm{~A}$-cells ( $\mathrm{IC}_{50}: 239.8 \mu \mathrm{M}$ ). Two additional flavonoids with similar structure, epicatechin, and quercetin, showed also strong inhibitory effects in both cell-types: epicatechin $\mathrm{IC}_{50}$ values were 96.6 $\mu \mathrm{M}\left(\mathrm{ScN}_{2} \mathrm{~A}\right.$-cells) and $106.8 \mu \mathrm{M}$ (SMB-cells) and quercetin $\mathrm{IC}_{50}$ values were $36.8 \mu \mathrm{M}\left(\mathrm{ScN}_{2} \mathrm{~A}\right.$-cells) and $274.3 \mu \mathrm{M}$ (SMB-cells; Table 1). Baicalein displayed a strong dose dependent inhibitory effects to $\mathrm{PrP}^{\mathrm{res}}$ formation $\left(\mathrm{IC}_{50}: 18.48 \mu \mathrm{M}\right.$ ) and dissolution of $\mathrm{PrP}^{\mathrm{Sc}}$ aggregates $\left(\mathrm{IC}_{50}: 41.56 \mu \mathrm{M}\right)$ in the cell-free conversion assay, in contrast to baicalin which yielded $\mathrm{IC}_{50}$ values of $>1000 \mu \mathrm{M}$ for $\mathrm{PrP}^{\mathrm{res}}$ inhibition and $440 \mu \mathrm{M}$ for $\mathrm{PrP}^{\mathrm{Sc}}$ dissolution. Epicatechin and quercetin, although highly similar in structural to baicalein, showed no inhibitory effects in cell-free conversion with regards to $\mathrm{PrP}^{\mathrm{res}}$ formation and $\mathrm{PrP}^{\mathrm{Sc}}$ disintegration.

In summary, these data demonstrate that tea of S. lateriflora contains two active compounds, baicalein and baicalin, which are specific inhibitors of $\mathrm{PrP}^{\mathrm{C}}$ conversion and $\mathrm{PrP}^{\text {res }}$ amplification in vitro as well as enhance the degradation of $\mathrm{PrP}^{\mathrm{Sc}}$ fibrils.
In another set of experiments in vivo effects of S. lateriflora tea were assessed. Wild-type mice were infected either by intracerebrally (i.c.) or intraperitoneally (i.p.) inoculation with mouse scrapie strain RML and the drinking water was replaced by freshly brewed tea starting 2 weeks prior to their inoculation and for the whole lifetime of the mice. Survival times are depicted in Figure 3. Six B16/C57 mice were used for the treatment and compared to six intracerebrally inoculated mice which received normal drinking water. The mean life spans of the control group (Figure 5A, bold line) was $147 \pm 3.1 \mathrm{dpi}$ (Figure 3B) whereas the tea treated mice (Figure 5A dashed line) survived significantly longer ( $184 \pm 26.7 \mathrm{dpi}$; Figure 3B). Three of the treated mice survived up to 60 days compared to the control mice. In the case of i.p. inoculation of RML strain, a mean prolongation of 15 days was achieved (Figures 3C,D). The mean incubation time of the control group (Figure 3C, bold line) was $191 \pm 8.6$ dpi (Figure 3D) whereas the tea treated mice (Figure 3C, dashed line) survived significantly longer $(206 \pm 8.6 \mathrm{dpi}$; Figure 3D).

Brains of the i.c. infected mice were subjected to comparative biochemical and immunohistochemical investigations. PrP immunoblot analysis revealed no differences of $\mathrm{PrP}^{\mathrm{Sc}}$ banding patterns and total amounts of $\mathrm{PrP}^{\mathrm{Sc}}$ in both groups. The $\mathrm{PrP}^{\mathrm{Sc}}$ content 
in all brains was analyzed after PK digestion and selective precipitation of $\mathrm{PrP}^{\mathrm{Sc}}$ from corresponding mouse brain homogenates with sodium phosphotungstic acid (Figure 4). No differences

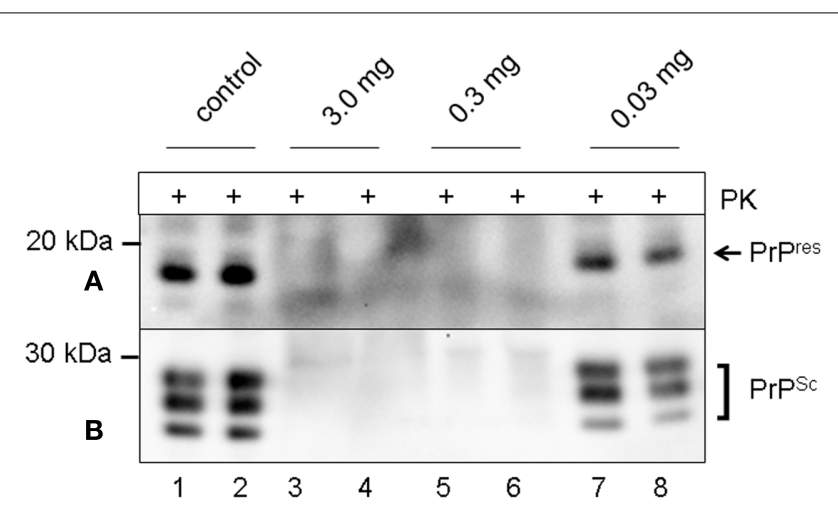

FIGURE 2 |Western blot analysis of inhibition of PrPres formation and disaggregation of pre-existing $\mathrm{PrP}^{\mathrm{Sc}}$ fibrils in a cell-free conversion assay. (A) Tea of S. lateriflora inhibits formation of PrPres. Lanes 1-2 show PK-resistant PrPres-fragments in samples without tea, lanes 3-4 samples after co-incubation with $3.0 \mathrm{mg}$ dried tea extract, lanes 5-6 with $0.3 \mathrm{mg}$ dried tea extract, and lanes 7-8 co-incubation with $0.03 \mathrm{mg}$ dried tea extract. Detection was carried out with mab P4. (B) Tea of S. lateriflora disaggregates pre-existing fibrils after digestion with PK. The membrane from (A) was stripped and incubated another time with pab Ra10. Lanes 1-2 show PK-resistant PrPres-fragments in samples without tea, lanes 3-4 samples after co-incubation with $3.0 \mathrm{mg}$ dried tea extract, lanes 5-6 with $0.3 \mathrm{mg}$ dried tea extract, and lanes $7-8$ co-incubation with $0.03 \mathrm{mg}$ dried tea extract. Western blot was analyzed by standard chemiluminescence method. +: incubation with proteinase $K(P K)$. in $\mathrm{PrP}^{\mathrm{Sc}}$ banding patterns or $\mathrm{PK}$ resistances was detected in mice which eventually developed scrapie in the tea treated and control group (Figure 4, lanes 2-13). The brain lesion profiles and $\mathrm{PrP}^{\mathrm{Sc}}$ deposition patterns in the different mouse brain regions were similar for the treated and the untreated mice (Figures 5A-D).

\section{DISCUSSION}

The here presented study demonstrates that solubilized ingredients of S. lateriflora not only inhibit the scrapie fibril formation but also destabilize pre-formed $\mathrm{PrP}^{\mathrm{Sc}}$ fibrils in a concentration dependent manner. Main constituents of the herb were the polyphenolic flavonoids baicalin and baicalein, which were found at high concentrations in corresponding extracts. Both components in purified form showed dose dependent inhibitory properties and thus were the active constituents responsible for the herbs effects on scrapie fibril regulation.

The strongest effects displayed baicalein, the main metabolite of baicalin, which inhibited $\mathrm{PrP}^{\text {res }}$ accumulation in both cell-based and cell-free assays and promoted the destabilization of $\mathrm{PrP}^{\mathrm{Sc}}$ fibrils at low concentrations. A possible molecular mechanism is based on direct binding to the $\operatorname{PrP}^{\mathrm{C}}$ and the formation of a stable PrP-baicalein/baicalin complex, which blocks PrP conversion and/or accumulation. In the same way the destabilization of pre-existing fibrils would be caused by a specific intercalation of baicalein/baicalin into $\beta$-sheet structures of the $\mathrm{PrP}^{\mathrm{Sc}}$ aggregates which may lead to a forced $\mathrm{PrP}^{\mathrm{Sc}}$ degradation by lysosomal proteases. Similar effects by Baicalein have been described for the inhibition of $\alpha$-synuclein (Zhu et al., 2004) and amyloid- $\beta$ peptide (A $\beta$ ) fibrillization (Lu et al., 2011).

Table 1 | Chemical structures of flavonoids and in vitro analyses.

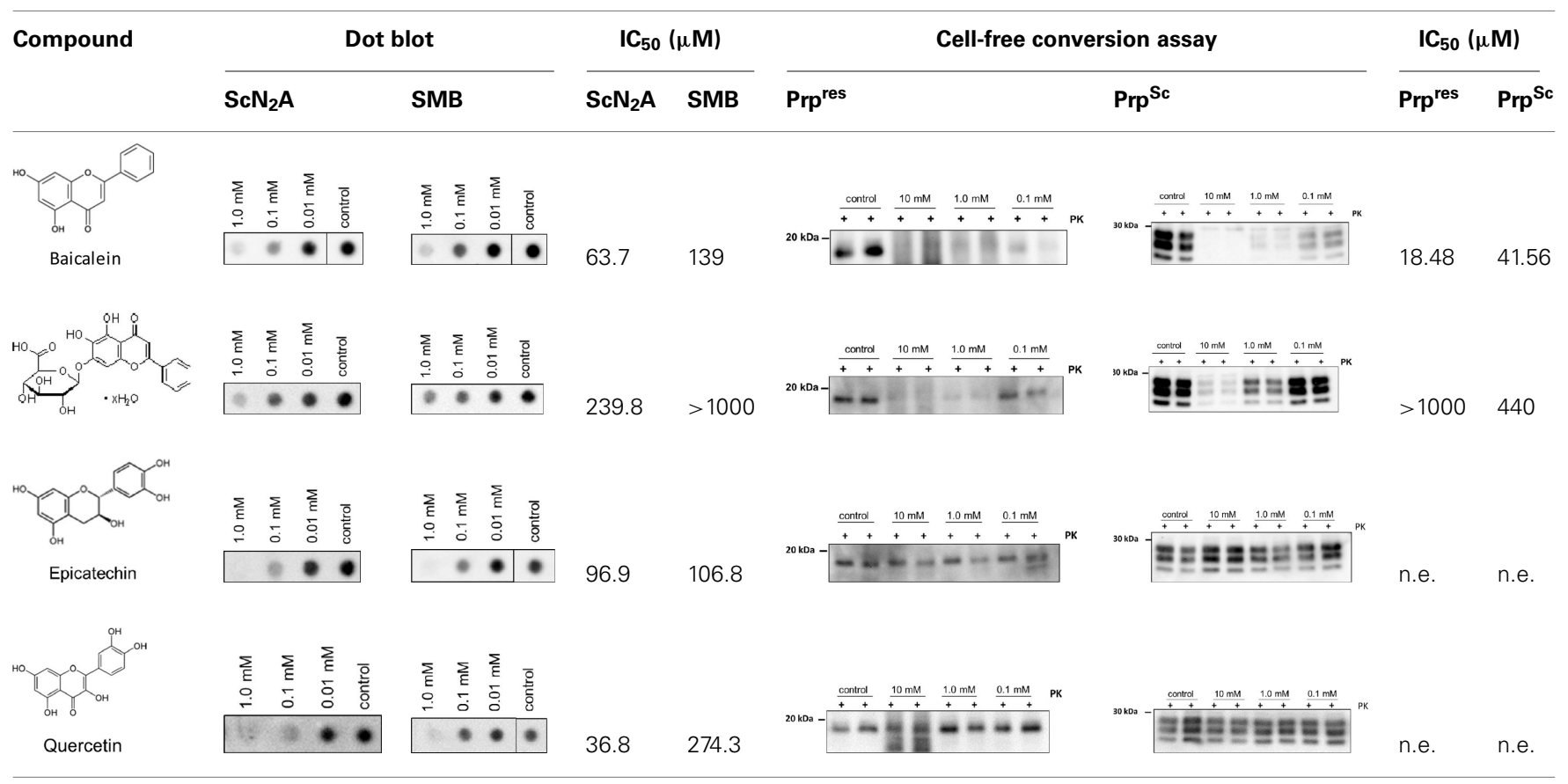

$I_{50}$. Half maximal (50\%) inhibitory concentration; n.e., not effective. 
A

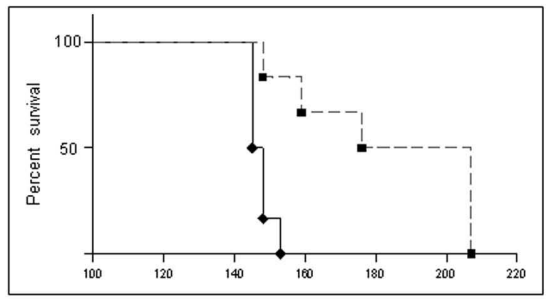

C

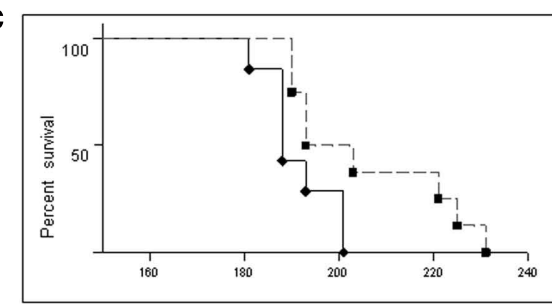

FIGURE 3 | Tea of $\boldsymbol{S}$. lateriflora prolongs incubation time in scrapie-infected mice after oral treatment. (A) Oral treatment of intracerebrally infected mice: Kaplan-Meier survival analysis of intracerebrally scrapie (RML) infected C57/B 6 mice after oral treatment with tea of $S$. lateriflora. Treatment groups consisted of untreated

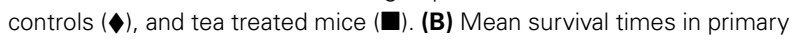
efficiency test \pm SD. Comparison of tea versus untreated controls was
B

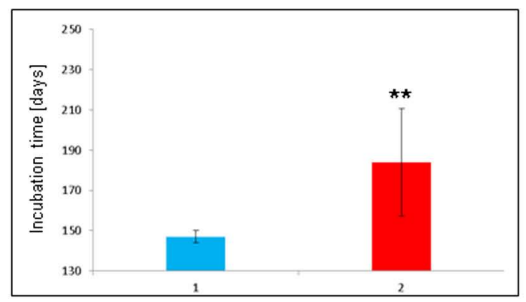

D

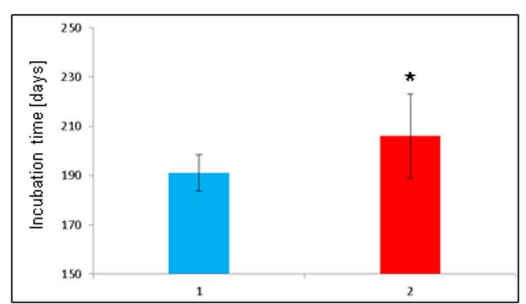

carried out by log-rank test, $p<0.01$ (**). (C) Oral treatment of intraperitoneally infected mice: Kaplan-Meier survival analysis of intraperitoneally scrapie (RML) infected C57/BI6 mice after oral treatment tea of $S$. lateriflora. Treatment groups consisted of untreated

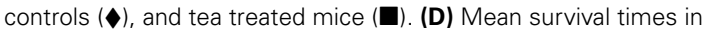
primary efficiency test \pm SD. Comparison of tea versus untreated controls, was carried out by log-rank test, $p<0.05(*)$.

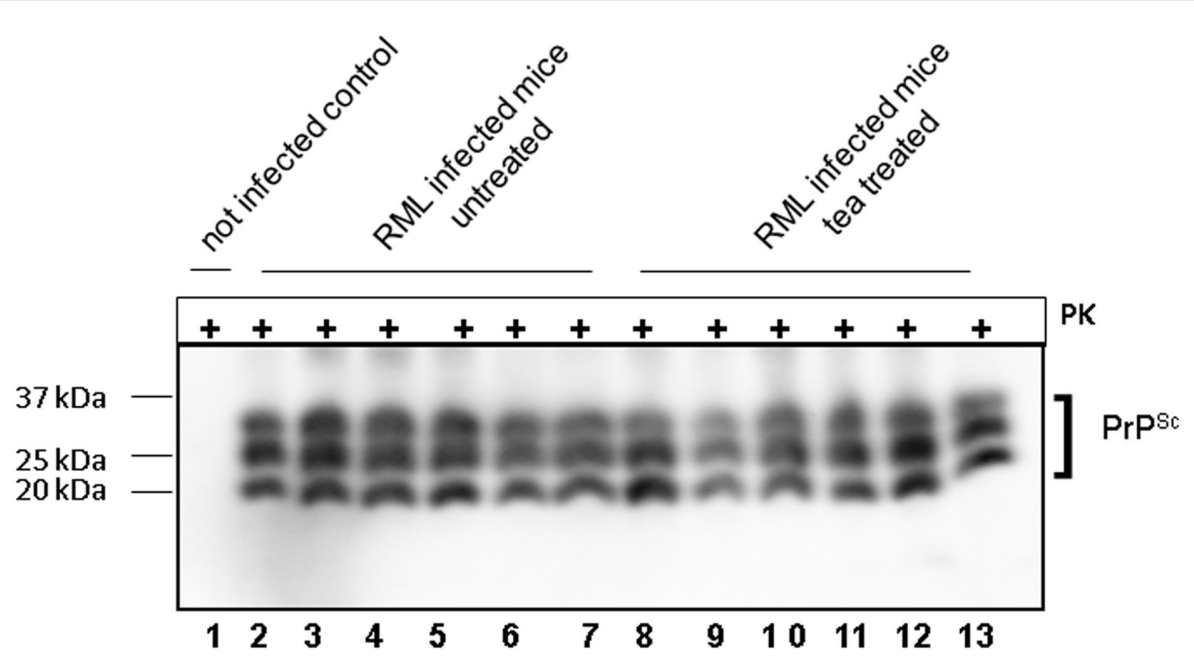

FIGURE 4 | Western blot analysis of sodium phosphotungstic acid precipitation of $\mathrm{PrP}^{\mathrm{Sc}}$ from brain homogenate of RML infected mice.

Proteinase $\mathrm{K}$ digested and sodium phosphotungstic acid precipitated PrPsc

was detected by mab SAF-70. Lane 1 shows an uninfected control, lanes 2-7
PrPsc from RML infected mouse brains and lanes 8-13 PrPsc from RML infected mouse brains that were treated with tea from $S$. lateriflora. Western blot was carried out with pab Ra10 and analyzed by chemiluminescence method.
In our present study oral administration of S. lateriflora tea significantly prolonged incubation of mice either infected intracerebral or intraperitoneal. These effects can be explained by direct interference of baicalein to evolving PrP aggregates in the CNS. Baicalein is able to cross the blood brain barrier and ultimately reach the CNS (Tsai et al., 2002). Baicalin, on the other hand, may act as pro-drug: After oral uptake, the sugar residue is cleaved by enzymes in the intestinal tract to generate baicalein. The more lipophilic baicalein is better absorbed in the gastrointestinal tract and can then enter the brain via the blood system (Tarragó et al., 2008).

Within the CNS, the inhibition and dissolution of prion aggregates by Baicalein could protect neuronal cells from membrane disruption and subsequent neuronal cell death. Additional antioxidant properties of baicalein on reactive oxygen species (ROS), which evolve during protein aggregation, may reinforce this 


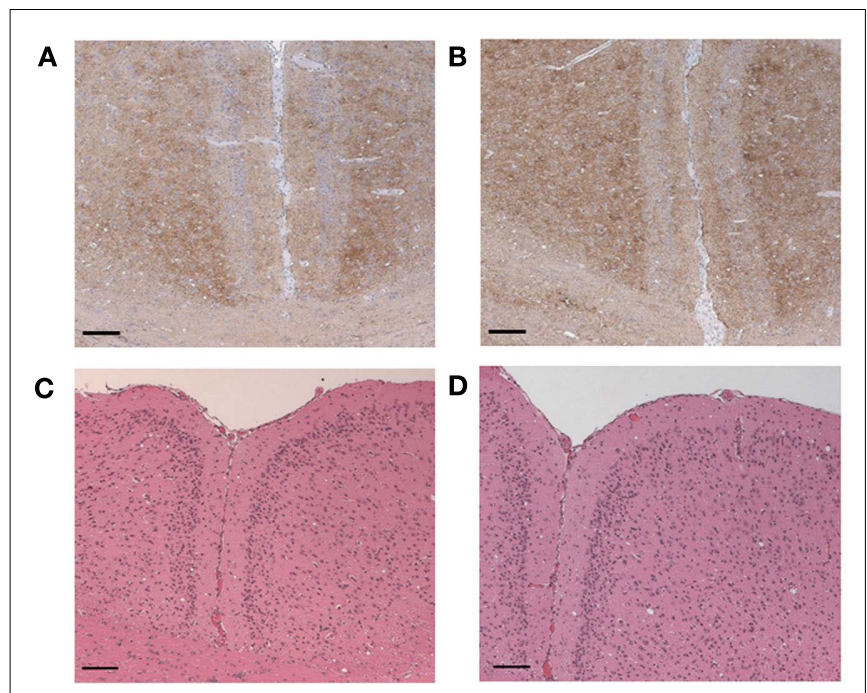

FIGURE 5 | PrPsc accumulation in the brains of mice challenged with RML. Immunohistochemistry: moderate diffuse $\mathrm{PrP}^{\mathrm{Sc}}$ accumulation in the cerebral cortex and multifocally in the corpus callosum of both (A) untreated and (B) with tea treated mice. Detection was carried out with mab SAF 84. Bar $200 \mu \mathrm{m}$. H\&E staining: mild vacuolation in the cerebral cortex of both (C) untreated and (D) with tea treated mice, H\&E staining, Bar $200 \mu \mathrm{m}$.

neuroprotective effect (Li et al., 2010). Baicalein is able to minimize ROS by directly quenching free radicals or indirectly inducing antioxidant enzymes like superoxide dismutase and catalase (Shieh et al., 2000; Kang et al., 2011).

Direct effects on the prion conversion were also seen in other plant derived polyphenols like curcumin which is a strong inhibitor of prion conversion replication in vitro (Caughey et al.,

\section{REFERENCES}

Adjou, K. T., Simoneau, S., Sales, N., Lamoury, F., Dormont, D., PapyGarcia, D., Barritault, D., Deslys, J. P., and Lasmezas, C. I. (2003). A novel generation of heparan sulfate mimetics for the treatment of prion diseases. J. Gen. Virol. 84, 2595-2603.

Awad, R., Arnason, J. T., Trudeau, V., Bergeron, C., Budzinski, J. W., Foster, B. C., and Merali, Z. (2003). Phytochemical and biological analysis of skullcap (Scutellaria lateriflora L.): a medical plant with anxiolytic properties. Phytomedicine 10, 640-643.

Caughey, B., and Race, R. E. (1992). Potent inhibition of scrapieassociated $\operatorname{PrP}$ accumulation by Congo red. J. Neurochem. 59, 768-771.

Caughey, B., Raymond, L. D., Raymond, G. J., Maxson, L., Silveira, J., and Baron, G. S. (2003). Inhibition of protease-resistant prion protein accumulation in vitro by curcumin. J. Virol. 77, 5499-5502.

Caughey, W. S., Priola, S. A., Kocisko, D. A., Raymond, L. D., Ward, A., and Caughey, B. (2007). Cyclic tetrapyrrole sulfonation, metals, and oligomerization in anti-prion activity. Antimicrob. Agents Chemother. 51, 3887-3894.

De Luigi, A., Colombo, L., Diomede, L., Capobianco, R., Mangieri, M., Miccolo, C., Limido, L., Forloni, G., Tagliavini, F., and Salmona, M. (2008). The efficacy of tetracyclines in peripheral and intracerebral prion infection. PLoS ONE 3, e1888. doi:10.1371/journal.pone. 0001888

Doh-Ura, K., Kuge, T., Uomoto, M., Nishizawa, K., Kawasaki, Y., and Iha, M. (2007). Prophylactic effect of dietary seaweed Fucoidan against enteral prion infection. Antimicrob. Agents Chemother. 51, 2274-2277.

Eiden, M., Palm, G. J., Hinrichs, W., Matthey, U., Zahn, R., and Groschup, M. H. (2006). Synergistic and strainspecific effects of bovine spongiform encephalopathy and scrapie prions in the cell-free conversion of recombinant prion protein. J. Gen. Virol. 87, 3753-3761.

2003). It is in vivo efficacy, however, remains controversial: the oral administration of curcumin had no significant effect on the onset of scrapie in hamsters (Caughey et al., 2003), whereas scrapie-infected mice significantly survived longer after oral treatment (Riemer et al., 2008). Effects of other polyphenols (e.g., tannic acid, katacine, and $2^{\prime}-2^{\prime \prime}$-bis epigallocatechin gallate) that interfere with $\operatorname{PrP}$ conversion in vitro were also studied in vivo (Kocisko et al., 2003). However, neither these substances nor mixtures of natural compounds including polyphenolic tea extract and pine bark extracts displayed any effects on incubation periods in scrapie-infected animals (Kocisko et al., 2004).

Up to now only few compounds have been reported that delay onset on prion diseases after oral treatment. This includes pravastatin (Vetrugno et al., 2009), which is involved in cholesterol biosynthesis and influences membrane structure and function, fucoidan (Doh-Ura et al., 2007), as well as amyloid dye derivatives (Kawasaki et al., 2007). However, possible drug associated sideeffects have to be further evaluated. Recently, diphenyl-pyrazoles (Leidel et al., 2011) were identified as a new class of anti-prion compounds, which prolong incubation time of scrapie-infected mice even after oral application.

In conclusion, beneficial effects of S. lateriflora tea can be explained by the anti-aggregatory and potential anti-oxidative effects of its natural constituents, baicalein and baicalin. Only few studies were conducted with herbal extracts of S. lateriflora for prevention and therapy of protein misfolding diseases to date. Results shown here for prion diseases are promising also in the context of other diseases in this group.

\section{ACKNOWLEDGMENTS}

The LCMS-IT-TOF analysis was carried out by Andreas Link and Andrea Bodtke, Institute of Pharmacy, Ernst-Moritz-ArndtUniversity Greifswald, Greifswald, Germany.

Foster, S. (1996). Scullcap: a Herbal Enigma. Business Herbs 1996, 14-16. Fraser, H., and Dickinson, A. G. (1968) The sequential development of the brain lesion of scrapie in three strains of mice. J. Comp. Pathol. 78, 301-311.

Fujiwara, H., Tabuchi, M., Yamaguchi, T., Iwasaki, K., Furukawa, K., Sekiguchi, K., Ikarashi, Y., Kudo, Y., Higuchi, M., Saido, T. C., Maeda, S., Takashima, A., Hara, M., Yaegashi, N., Kase, Y., and Arai, H. (2009). A traditional medicinal herb Paeonia suffruticosa and its active constituent 1,2,3,4,6-penta- $O$ galloyl-beta-D-glucopyranose have potent anti-aggregation effects on Alzheimer's amyloid beta proteins in vitro and in vivo. J. Neurochem. 109, 1648-1657.

Geissen, M., Leidel, F., Eiden, M. Hirschberger, T., Fast, C., Bertsch, U., Tavan, P., Giese, A., Kretzschmar, H., Schatzl, H. M., and Groschup, M. H. (2011). From highthroughput cell culture screening to mouse model: identification of new inhibitor classes against prion disease. ChemMedChem 6, 1928-1937.

Gretzschel, A., Buschmann, A., Eiden, M., Ziegler, U., Lühken, G., Erhardt G., and Groschup, M. H. (2005) Strain typing of German transmissible spongiform encephalopathies field cases in small ruminants by biochemical methods. J. Vet. Med. B Infect. Dis. Vet. Public Health 52, 55-63.

Groschup, M. H., Harmeyer, S., and Pfaff, E. (1997). Antigenic features of prion proteins of sheep and of other mammalian species. J. Immunol. Methods 207, 89-101.

Groschup, M. H., Langeveld, J., and Pfaff, E. (1994). The major species specific epitope in prion proteins of ruminants. Arch. Virol. 136, 423-431.

Hardt, M., Baron, T., and Groschup, M. H. (2000). A comparative study of immunohisto-chemical methods for detecting abnormal prion protein with monoclonal and polyclonal antibodies. J. Comp. Pathol. 122, 43-53. 
Heiseke, A., Aguib, Y., Riemer, C., Baier, M., and Schätzl, H. M. (2009). Lithium induces clearance of protease resistant prion protein in prion-infected cells by induction of autophagy. J. Neurochem. 109, 25-34.

Horiuchi, M., Priola, S. A., Chabry, J., and Caughey, B. (2000). Interactions between heterologous forms of prion protein: binding, inhibition of conversion, and species barriers. Proc. Natl. Acad. Sci. USA 97, 5836-5841.

Jarrett, J. T., and Lansbury, P. T. (1993). Seeding "one-dimensional crystallization" of amyloid: a pathogenic mechanism in Alzheimer's disease and scrapie? Cell 18, 1055-1058.

Kang, K. A., Zhang, R., Piao, M. J., Chae, S., Kim, H. S., Park, J. H., Jung, K. S., and Hyun, J. W. (2011). Baicalein inhibits oxidative stressinduced cellular damage via antioxidant effects. Toxicol. Ind. Health doi:10.1177/0748233711413799

Kawasaki, Y., Kawagoe, K., Chen, C. J., Teruya, K., Sakasegawa, Y., and Doh-ura, K. (2007). Orally administered amyloidophilic compound is effective in prolonging the incubation periods of animals cerebrally infected with prion diseases in a prion strain-dependent manner. $J$. Virol. 81, 12889-12898.

Kocisko, D. A., Baron, G. S., Rubinstein, R., Chen, J., Kuizon, S., and Caughey, B. (2003). New inhibitors of scrapieassociated prion protein formation in a library of 2000 drugs and natural products. J. Virol. 77, 10288-10294.

Kocisko, D. A., Morrey, J. D., Race, R. E., Chen, J., and Caughey, B. (2004). Evaluation of new cell culture inhibitors of protease-resistant prion protein against scrapie infection in mice. J. Gen. Virol. 85, 2479-2483.

Kupfer, L., Eiden, M., Buschmann, A., and Groschup, M. H. (2007). Amino acid sequence and prion strain specific effects on the in vitro and in vivo convertibility of ovine/murine and bovine/murine prion protein chimeras. Biochim. Biophys. Acta. 1772, 704-713.

Leidel, F., Eiden, M., Geissen, M., Kretzschmar, H. A., Giese, A., Hirschberger, T., Tavan, P., Schätzl,
H. M., and Groschup, M. H. (2011). Diphenylpyrazole-derived compounds increase survival time of mice after prion infection. Antimicrob. Agents Chemother. 55, 4774-4781.

Li, C. T., Zhang, W. P., Fang, S. H., Lu, Y. B., Zhang, L. H., Qi, L. L., Huang, X. Q., Huang, X. J., and Wei, E. Q. (2010). Baicalin attenuates oxygen-glucose deprivationinduced injury by inhibiting oxidative stress-mediated 5-lipoxygenase activation in PC12 cells. Acta Pharmacol. Sin. 31, 137-144.

Liu, P., Kemper, L. J., Wang, J., Zahs, K. R., Ashe, K. H., and Pasinetti, G. M. (2011). Grape seed polyphenolic extract specifically decreases $a \beta * 56$ in the brains of $\operatorname{tg} 2576$ mice. J. Alzheimers Dis. 26, 657-666.

Lu, J. H., Ardah, M. T., Durairajan, S. S., Liu, L. F, Xie, L. X., Fong, W. F., Hasan, M. Y., Huang, J. D., El-Agnaf, O. M., and Li, M. (2011). Baicalein inhibits formation of $\alpha$-synuclein oligomers within living cells and prevents a $\beta$ peptide fibrillation and oligomerization. Chembiochem 12, 615-624.

Mange, A., Nishida, N., Milhavet, O., McMahon, H. E., Casanova, D., and Lehmann, S. (2000). Amphotericin $B$ inhibits the generation of the scrapie isoform of the prion protein in infected cultures. J. Virol. 74, 3135-3140.

Murakami-Kubo, I., Doh-Ura, K., Ishikawa, K., Kawatake, S., Sasaki, K., Kira, J., Ohta, S., and Iwaki, T. (2004). Quinoline derivatives are therapeutic candidates for transmissible spongiform encephalopathies. J. Virol. 78, 1281-1288.

Pfeifer, A., Eigenbrod, S., Al-Khadra, S., Hofmann, A., Mitteregger, G., Moser, M., Bertsch, U., and Kretzschmar, H. (2006). Lentivector-mediated RNAi efficiently suppresses prion protein and prolongs survival of scrapieinfected mice. J. Clin. Invest. 116, 3204-3210.

Priola, S. A., Raines, A., and Caughey, W. S. (2000). Porphyrin and phthalocyanine antiscrapie compounds. Science 287, 1503-1506.

Proske, D., Gilch, S., Wopfner, F., Schätzl, H. M., Winnacker, E. L., and
Famulok, M. (2002). Prion-proteinspecific aptamer reduces PrPSc formation. Chembiochem 3, 717-725.

Rezai-Zadeh, K., Shytle, D., Sun N., Mori, T., Hou, H., Jeanniton, D., Ehrhart, J., Townsend, K., Zeng, J., and Morgan, D. (2005). Green tea epigallocatechin-3-gallate (EGCG) modulates amyloid precursor protein cleavage and reduces cerebral amyloidosis in Alzheimer transgenic mice. J. Neurosci. 25, 8807-8814.

Riemer, C., Burwinkel, M., Schwarz, A. Gültner, S., Mok, S. W., Heise, I., Holtkamp, N., and Baier, M. (2008). Evaluation of drugs for treatment of prion infections of the central nervous system. J. Gen. Virol. 89, 594-597.

Shieh, D. E., Liu, L. T., and Lin, C. C. (2000). Antioxidant and free radical scavenging effects of baicalein, baicalin and wogonin. Anticancer Res. 20, 2861-2865.

Soto, C., and Estrada, L. D. (2008). Protein misfolding and neurodegeneration. Arch. Neurol. 65, 184-189.

Supattapone, S., Wille, H., Uyechi, L., Safar, J., Tremblay, P., Szoka, F. C., Cohen, F. E., Prusiner, S. B., and Scott, M. R. (2001) Branched polyamines cure prioninfected neuroblastoma cells. $J$. Virol. 75, 3453-3461.

Tarragó, T., Kichik, N., Claasen, B. Prades, R., Teixidó, M., and Giralt, E. (2008). Baicalin, a prodrug able to reach the CNS, is a prolyl oligopeptidase inhibitor. Bioorg. Med. Chem. 16, 7516-7524.

Tsai, T. H., Liu, S. C., Tsai, P. L., Ho, L. K. Shum, A. Y., and Chen, C. F. (2002) The effects of the cyclosporine A, a Pglycoprotein inhibitor, on the pharmacokinetics of baicalein in the rat: a microdialysis study. Br. J. Pharmacol. 137, 1314-1320.

Vetrugno, V., Di Bari, M. A., Nonno, R. Puopolo, M., D’Agostino, C., Pirisinu, L., Pocchiari, M., and Agrimi, U. (2009). Oral pravastatin prolongs survival time of scrapie-infected mice. J. Gen. Virol. 90, 1775-1780.

Wang, Y. J., Thomas, P., Zhong, J. H., Bi, F. F., Kosaraju, S., Pollard, A., Fenech, M., and Zhou, X. F. (2009). Consumption of grape seed extract prevents amyloid-beta deposition and attenuates inflammation in brain of an Alzheimer's disease mouse. Neurotox. Res. 15, 3-14.

White, A. R., Enever, P., Tayebi, M., Mushens, R., Linehan, J., Brandner, S., Anstee, D., Collinge, J., and Hawke, S. (2003). Monoclonal antibodies inhibit prion replication and delay the development of prion disease. Nature 422, 80-83.

Yang, F., Lim, G. P., Begum, A. N., Ubeda, O. J., Simmons, M. R., Ambegaokar S. S., Chen, P. P., Kayed, R., Glabe, C. G., Frautschy, S. A., and Cole, G. M. (2009). Curcumin inhibits formation of amyloid beta oligomers and fibrils, binds plaques, and reduces amyloid in vivo. J. Biol. Chem. 280, 5892-5901.

Zhu, M., Rajamani, S., Kaylor, J., Han, S., Zhou, F., and Fink, A. L. (2004). The flavonoid baicalein inhibits fibrillation of alpha-synuclein and disaggregates existing fibrils. J. Biol. Chem. 279, 26846-26857.

Conflict of Interest Statement: The authors declare that the research was conducted in the absence of any commercial or financial relationships that could be construed as a potential conflict of interest.

Received: 12 December 2011; paper pending published: 30 December 2011; accepted: 02 February 2012; published online: 17 February 2012.

Citation: Eiden M, Leidel F, Strohmeier B, Fast $C$ and Groschup MH (2012) A medicinal herb Scutellaria lateriflora inhibits $\operatorname{Pr} P$ replication in vitro and delays the onset of prion disease in mice. Front. Psychiatry 3:9. doi: 10.3389/fpsyt.2012.00009

This article was submitted to Frontiers in Neurodegeneration, a specialty of Frontiers in Psychiatry.

Copyright (C) 2012 Eiden, Leidel, Strohmeier, Fast and Groschup. This is an open-access article distributed under the terms of the Creative Commons Attribution Non Commercial License, which permits non-commercial use, distribution, and reproduction in other forums, provided the original authors and source are credited. 